\title{
Peregrinação, conquista e povoamento. Mito e "realismo desencantado" numa hagiografia medieval portuguesa
}

Néri de Almeida Souza

Universidade Estadual Paulista - UNESP

\begin{abstract}
RESUMO
O texto pretende realizar uma interpretação da narrativa de viagem ao Paraíso Terrestre cistercience Vida de Santo Amaro, à luz da história portuguesa entre os séculos XIII e XV, apontando as relações existentes entre pensamento histórico e pensamento mítico na passagem do processo de Reconquista para os Descobrimentos, vivenciados ao longo da história das diferentes versões escritas da fonte analisada.

Palavras-chave: hagiografia; Portugal; paraíso terrestre.
\end{abstract}

\begin{abstract}
The text intents to interpret the Cistercian Earthly Paradise voyage narrative, Vida de Santo Amaro, according to the 13th through 15th century Portuguese history. It shows the relationship between the historical and mythical mind from the Reconquest process passage to the Discovery Era. It was experienced along the history of different written versions of the source analyzed.

Keywords: hagiography; Portugal; earthly paradise.
\end{abstract}


A despeito das ilusões que o aparente tumulto das agitações superficiais [causadas pelos eventos] pode manter, é sempre a bem longo prazo que suas ressonâncias terminam em desabamentos [do sistema cultural], os quais são sempre parciais e deixam sempre subsistir irredutíveis vestígios." ${ }^{1}$

Esse momento de universalidade - mais sonhado do que real -, justificado menos por qualquer potência temporal do que pela irradiação de uma fé, vivida como luz e dom de Deus, tornar-se-á para os portugueses aquele lugar onde eles se vêem, ao mesmo tempo maiores e mais pequenos do que são. Essa identidade mítica, razão de sua estranheza e do seu mistério, é o seu céu e a sua cruz...Desde os tempos mais recuados que essa terra, Atlântida sem lembrança dela, parece desertar a Europa. Por necessidade ou por cupidez, raro por aventura, os portugueses partiram dela ao longo dos séculos, por vezes sem esperança de regresso. A longa história de Portugal, incluindo nela a anterior ao seu nascimento como reino, é a de uma deriva e de uma fuga sem fim...passado-presente, que a alma portuguesa não quer abandonar...cavaleiros do Graal adormecidos, mas de pé, imóveis, no coração da realidade. ${ }^{2}$

A hagiografia medieval é um gênero literário que deriva de um movimento complexo entre a memória oral e escrita do período. As conseqüências históricas desta simples constatação ainda permanecem obscurecidas por uma leitura da hagiografia que privilegia seu papel espiritual, moralizador e edificante. A Vida de Santo Amaro é um exemplo de como a composição, o significado e a atuação histórica da hagiografia podem ultrapassar estes limites.

A legenda ${ }^{3}$ de Santo Amaro faz parte da Colecção Mystica de Fr. Hylario de Lourinhã, pertencente à biblioteca do mosteiro cistercience português de Alcobaça. A edição que utilizamos foi publicada em 1901 por Otto Klob sob o nome de Vida de Santo Amaro ${ }^{4}$. Embora o texto permaneça carente de uma edição crítica mais cuidadosa ${ }^{5}$, como pretendemos mostrar, sua importância justifica uma primeira abordagem histórica geral a partir da leitura feita por Otto Klob. A riqueza deste documento reside na complexidade de sua composição e divulgação, traço comum às fontes medievais. O exemplar editado por Klob, escrito em língua portuguesa, data do século XV. Sua unidade lingüística, porém, permite afirmar que se trata de cópia de uma versão do século anterior. A comparação do texto português com uma versão espanhola datada do século XVI indica que ambas se baseiam em um mesmo original composto em latim no século XIII. Assim, um período relativamente amplo e extremamente rico da vida ibérica dá consistência histórica a esta versão da legenda.

A Vida de Santo Amaro traz uma série de indícios da forte intertextualidade atuante em sua composição. Este aspecto, nada incomum às fontes do pe- 
ríodo, assegura que os elementos do relato conheceram - sob formas que são sempre difíceis de definir para as fontes medievais -, uma difusão que ultrapassa largamente sua forma escrita. A transcrição da legenda para o vernáculo confirma esta constatação, e aponta para o apelo positivo dos elementos do relato sobre o público ao qual se destinava. A própria estrutura do texto testemunha sua proximidade com a linguagem litúrgica e a orientação oral e ritual de sua função 6 . Os diferentes usos e interpretações da legenda de Amaro, ao longo dos séculos de sua história documentada, parecem implícitos nos conflitos que envolvem sua intitulação. Segundo O. Klob, o título Vida de Santo Amaro está inscrito no alto da página do manuscrito em que se inicia o texto, mas que ainda contém a continuação de uma narrativa anterior, a Contemplação de São Bernardo (p.505). O texto da legenda, no entanto, inicia-se com a inscrição "Conto deamaro" (p.507). Já no catálogo do mosteiro, o relato consta sob a rubrica "Historia cujusdam Mauri qui concupivit videre paradisum terrestrem" (p.504). Porém, o mais forte sinal de intertextualidade da fonte encontra-se na própria natureza da narrativa, ligada à tradição mítica dos relatos de viagens ao Além.

$\mathrm{Na}$ versão portuguesa da legenda, Amaro não é explicitamente chamado de santo. Todavia, seu comportamento contrito, os eventos maravilhosos cristãos e o fechamento da legenda com a alusão a seus milagres post mortem não deixam dúvidas de que se tinha a intenção de dar à narrativa um estatuto hagiográfico. Mas esta vida de santo causa estranheza, sobretudo, por dois motivos. Primeiramente, pelo desequilíbrio temático de sua composição: dados que geralmente se repetem e se equilibram em relatos contemporâneos de vidas de santos - origem familiar, a condição social, a procedência geográfica, a vocação e a conversão religiosas, os sofrimentos, o detalhamento dos feitos milagrosos e da morte do santo - estão ausentes na Vida de Santo Amaro, ou são sumariamente apresentados no início e no final do relato. Em segundo lugar, esses elementos cedem espaço a um grande tema pouco freqüente na hagiografia, que é a viagem marítima ao Paraíso Terrestre. A versão portuguesa é ainda mais restrita que a espanhola. Quase todas as informações anteriores à viagem são suprimidas. A legenda portuguesa foi composta com a intenção de contar o relato da viagem do santo ao Além. O objetivo do texto fica claro já no início do primeiro parágrafo: "Conta que em huua provjcia auya huu hõem bóó que auya nome amaro, e que diz que auja grã desejo deueer o parayso terreall e que nuca folgaua se nõ quando ouuya fallar e elle"(p.507). Se não podemos duvidar de que existia o propósito de se santificar a viagem e seu protagonista, estes dados nos permitem ao menos desconfiar de que o alvo do autor ou autores - considerando-se a ação autoral dos "copistas" e a interferência da di- 
fusão oral na forma da tradição ${ }^{7}$ - fosse em primeiro lugar a exaltação da memória de um santo.

$\mathrm{Na}$ viagem de Santo Amaro - que transcorre ao longo de cinco ancoragens - o espaço atua como forte referencial simbólico. Depois de se entregar ao mar, sob os auspícios de uma voz que assim ordenava, Amaro e seus companheiros de viagem chegam a uma pequena ilha (jnssoa pequena) (p.507) habitada por leões e por um eremita que não o reconhece. Segue-se uma ilha grande (jnsoa grande) (p.508) habitada por homens luxuriosos, onde existem cinco castelos. Chegam então ao Mar Vermelho, cuja travessia altera qualitativamente as experiências dos viajantes. Passado o Mar Vermelho, Amaro chega a uma ilha muito grande (jnssoa muy grande) (p.508) e rica, habitada por pessoas belas, corteses, saudáveis e longevas. De volta ao mar, a nau do santo é atraída para uma região de calmaria, onde animais marinhos devoram os corpos dos tripulantes, mortos pela fome, de sete naus encalhadas. Salvos pela Virgem, Amaro e seus companheiros chegam a uma "terra" chamada "Ilha Deserta" (jnssoa deserta) (p.510), na qual encontram uma enorme abadia cercada por animais perigosos. Ali Amaro recebe de um eremita sua primeira orientação objetiva de viagem: ir contra o nascente (contra hu nace osol) (p.510). Chega assim a uma "terra" (p.510) na qual finalmente irá encontrar o Paraíso Terrestre. Amaro então deixa seus companheiros na praia e segue sozinho em sua busca. A certa altura encontra Leomites, um monge cistercience que, embora sem nunca tê-lo visto, sabia quem era Amaro e o que buscava. Depois de passar quarenta dias no mosteiro Vale das Flores com Leomites, o santo recebe dele instruções para se deslocar em direção a uma outra região da mesma terra. Após viajar pela costa e atravessar um rio, Amaro chega a um vale, onde encontra dois eremitas solitários e um mosteiro feminino chamado Flor das Damas. Nele, depois de longa penitência, Amaro é visitado por Válides, uma eremita que o conduz à base da montanha do Paraíso Terrestre (p.515). Amaro sobe a montanha e chega aos portões do Paraíso onde descobre que não lhe será permitido entrar. De fora, o santo vê em um maravilhoso pomar, povoado de sons, cores e aromas deliciosos, uma corte festiva no centro da qual impera uma bela e graciosa dama, a Virgem. A duração dessa visão extraordinária para Amaro tem o sabor de um pequeno instante. Fora daquele lugar especial, no entanto, haviam-se passado 267 anos. Sabendo disso, Amaro pede ao guarda dos portões que lhe dê uma escudela com a terra do lugar. Com a escudela em suas mãos o santo deixa a montanha e volta para o local em que deixara seus companheiros de viagem.

A cultura medieval teve especial apreço pelos relatos de viagens ao Além. Este tema antiqüíssimo - cujas raízes muitos remontam às origens do homem -, tinha contudo a propriedade especial de prestar-se bem ao reaproveitamento pe- 
la cultura teológica cristã, sem perder de todo seu aspecto mítico e folclórico ${ }^{8}$. A capacidade de adaptação deste tema da cultura folclórica ao discurso eclesiástico permitiu que ao seu fascínio se somassem formas mais evolutivas do relato erudito, ${ }^{9}$ tornando-o meio mais eficiente de comunicação entre clérigos e leigos e, dessa forma, de disciplinamento religioso e ideológico. As narrativas medievais de viagens marítimas ao Além remontam à tradição irlandesa. Na Navegação de Mäel-Duine - o relato ocidental mais antigo desta matéria datado do século VIII - encontramos elementos similares aos da viagem de Amaro: ancoragens e zarpagens sucessivas em diferentes ilhas, alternância entre escalas perigosas e outras agradáveis e edificantes, forte conteúdo maravilhoso expresso através de fartura e alegria desmedidas, de animais fabulosos, etc. O encontro deste tema de viagens marítimas a mundos maravilhosos com a hagiografia não é exclusivo da Vida de Santo Amaro. O relato mais conhecido a fazer a aproximação dos dois universos temáticos é Le voyage de Saint Brandan ${ }^{10}$. Composto para a corte anglo-normanda entre os séculos XII e XIII, este texto provavelmente é produto da cristianização da narrativa folclórica irlandesa da viagem de Bran ${ }^{11}$. A Vida de Santo Amaro, portanto, deve ser entendida considerando-se as duas direções apontadas pelo seu texto: a de sua inserção numa tradição muito antiga de relatos, e a das razões e significados de suas especificidades. À consideração do documento dentro de uma tradição temporal e geograficamente ampla, que ultrapassa sua realização material, deve somar-se a observação das oscilações internas de seu conteúdo, devidas à intertextualidade e a fatores conjunturais.

Inúmeras aproximações podem ser observadas entre nosso documento e a viagem de São Brandão, bem conhecida em Portugal no período de vernacularização da Vida de Santo Amaro. Tanto Amaro quanto Brandão desejam e pedem a Deus a graça de contemplar o Paraíso Terrestre e procedem, com companheiros, a uma viagem cheia de escalas fabulosas, que objetiva atingi-lo. Se as similaridades chamam nossa atenção para o núcleo comum que devia constituir o foco de atração do público para o relato, e nos remete para a sensibilidade narrativa do período, é nas diferenças entre os dois textos que podemos identificar as pressões históricas que - voluntária ou involuntariamente -, foram somadas à tradição mítica. As diferenças mais significativas entre os dois relatos aparecem na representação de sua instância simbólica essencial, o espaço. Na viagem de São Brandão, o santo viaja longamente pelo espaço do Além, no qual Inferno, Paraíso (identificável ao Paraíso Terrestre) e um espaço hierarquicamente superior vedado aos mortais (identificável ao Paraíso Celeste) sucedem-se num mesmo plano espacial contíguo ao espaço do Aqui. Na viagem de Santo Amaro, diferentemente, há descontinuidade de planos entre as diferentes seções do espaço. O Paraíso Terrestre situa-se em uma terra isolada das demais ilhas visitadas. Ama- 
ro, diferentemente de Brandão, não pode entrar no Paraíso Terrestre. A razão é a mesma pela qual Brandão não pode entrar no Paraíso Celeste: trata-se de um espaço reservado apenas aos mortos. Amaro pode apenas contemplar o Paraíso Terrestre do lado de fora de seus portões. Tomando-se como referência a condição do visitante, as duas narrativas apresentam uma importante diferença na forma de conceber as relações entre os espaços do Aqui e do Além, que num caso são contínuos e no outro descontínuos. Enquanto na viagem de São Brandão somente o Paraíso Celeste é inacessível aos vivos, na Vida de Santo Amaro o Paraíso Terrestre se torna inatingível àqueles que logram chegar às suas portas. Este espaço está doravante destinado apenas à contemplação dos viajantes predestinados. À fronteira temporal que distinguia Aqui e Além soma-se a inacessibilidade espacial, que afasta mundo terreno e ultraterreno, abrindo uma fenda entre o universo objetivo e o subjetivo.

A Vida de Santo Amaro guarda ainda uma originalidade mais significativa e que aparentemente lhe é exclusiva no conjunto dos relatos de viagens ao Além. Nesta tradição, a jornada do viajante se encerra apenas depois do retorno ao ponto de partida, seja a casa familiar ou o mosteiro. Logo depois deste retorno ocorre a morte do herói, que já não pode viver em um tempo que não é o seu, uma vez que experimentou da temporalidade maravilhosamente dilatada do Além. A volta do viajante à sua comunidade original assegura a divulgação do evento, testifica a veracidade do relato de sua viagem, e realimenta o mito da existência do Além e da possibilidade de trânsito entre as esferas da realidade ${ }^{12}$. Mas, depois de contemplar o Paraíso Terrestre, Amaro pede ao porteiro que lhe dê uma porção da terra do lugar, desce a montanha e encontra no local em que deixara seus companheiros uma "muy gram cidade" (p.517) por eles povoada. Permanece nela por algum tempo e logo parte, movido pelo desejo de povoar. Em um vale cercado por três rios, Amaro encontra "das mais bellas terras queno m udo podya seer” (p.518), localizadas próximas ao mosteiro feminino em que se penitenciara no passado. Sobre elas despeja a escudela de terra que trouxera do Paraíso e aí funda uma cidade, que se torna logo populosa graças à atração de sua fertilidade maravilhosa, uma vez que "cresciã aly as aruores e hu u año mais que em outro logar em cinquo" (p.518).

O desfecho da Vida de Santo Amaro não contraria apenas a tradição dos relatos de viagens ao Além, mas parece estabelecer uma contradição com a própria estrutura interna da fonte. Talvez não exista no texto elemento mais notável que a predisposição de Amaro para submeter a si mesmo, entregando-se ao mar, mergulhando no desconhecido sem orientação a seguir, vivendo da antevisão do Paraíso Terrestre que uma voz misteriosa lhe prometera. A respeito de Amaro muito pouco é dito. Sabe-se apenas que era bom e que desejava ver o Paraíso Ter- 
restre. $\mathrm{O}$ texto não fixa uma imagem física do santo mas prioriza a caracterização moral de Amaro, baseada numa interioridade completamente dobrada à vontade de Deus. O obscurecimento de sua personalidade e história pessoal reforça sua resignação e obediência à determinação externa de seu destino. A legenda salienta seus gestos de humildade e passividade, valorizando uma espiritualidade que propunha extorquir do corpo forças e do espírito vontade como condição para a aproximação de Deus, divindade tão fatal quanto o destino e tão insondável quanto o mar, pelo qual vagava a frágil nau de Amaro. Mas na conclusão do relato, Amaro, que havia até então se resignado a seu destino, que desejara o $\mathrm{Pa}$ raíso e aceita tê-lo apenas como visão para depois perdê-lo novamente, se transforma. Torna-se autônomo, decide, planeja, realiza, transforma, recria o espaço com a escudela de terra que trouxera do Paraíso.

A observação da Vida de Santo Amaro do ponto de vista do cruzamento dos contextos amplo e restrito que deságuam na legenda portuguesa evoca três problemas gerais intimamente relacionados: os motivos da versão precoce para o vernáculo desta hagiografia, a importância do reaproveitamento do tema mítico da viagem ao Além pelo gênero hagiográfico extraído de um ambiente religioso então em decadência - a ordem cisterciense, eclipsada em Portugal desde meados do século XIII pela presença mendicante, sobretudo franciscana-, e as especificidades da legenda em relação à tradição folclórica e suas razões conjunturais. Limitamo-nos aqui a apresentar algumas considerações gerais a respeito destas questões.

Dentre todas as peculiaridades da Vida de Santo Amaro, uma das mais notáveis é, sem dúvida, a ausência do diabo. Nem ele nem seus acólitos aparecem como promotores das desventuras e sofrimentos dos santos - papel que lhes é próprio na hagiografia. Na legenda de Amaro, o mal toma outras formas: está localizado na natureza desconhecida e irresistível e no interior do homem, em seus temores e fraquezas. O desejo pio de Amaro, movido pelos relatos sobre o Paraíso, sua passividade em face do desespero de seus companheiros desorientados diante do desconhecido, apontam um modelo moral pleno de resignação. Porém, observando mais atentamente a entrega de Amaro, vemos que a contradição entre seu perfil resignado e empreendedor não é absoluta. Da mesma forma que a carência - material, espiritual ou sensorial? - motiva Amaro a procurar o Paraíso Terrestre, a inacessibilidade última deste Além marcado pela riqueza sensorial - juventude, cores, sons melodiosos, fartura alimentar, onde civilização e cultura se equilibram num cenário de abundância prodigiosa - motiva-o a buscar uma saída para esta perda. Perda da única fonte de recursos definitiva, que deixa como alternativa apenas o mundo objetivo, parcialmente sacralizado pela terra escolhida por Amaro localizada próximo a um mosteiro de santas mu- 
lheres e pela benção da escudela por ele vertida. O "paraíso" criado por Amaro brota de sua sujeição ao fato de o Paraíso Terrestre estar, por hora, irremediavelmente perdido.

A Vida de Santo Amaro acompanha o processo promovido pela Igreja reformada que, entre os séculos XII e XIII ${ }^{13}$, foi paulatinamente realizando através da evangelização o disciplinamento, segundo valores cristãos, das representações do Além e das relações entre vivos e mortos. Como conseqüência geral dessa estratégia de doutrinamento, a faceta folclórica do Além - ainda significativa no Paraíso Terrestre fértil e festivo de Amaro - tende a dissolver-se. Em contrapartida, o Além ganha uma coloração teológica mais precisa para os cristãos comuns, espiritualizando-se. Sua conquista passa a ligar-se firmemente às noções abstratas de mérito, culpa e castigo, ao mesmo tempo em que seu espaço se hierarquiza e se define com clareza num "outro lugar". Amaro perde o Paraíso Terrestre, mas não perde a confiança em sua existência. Carência e fé cimentam a peregrinação conquistadora de Amaro, que motiva sua redescoberta do "paraíso" numa idealização nova, situada no mundo terreno construído pelo trabalho e pela vontade humana.

A ausência do diabo na legenda de Amaro acentua uma outra mais significativa, que confirma a função elementar desempenhada pelo espaço na elaboração da narrativa, aquela das localidades infernais. Novamente a viagem de São Brandão pode nos fornecer referências preciosas. Nela, os espaços infernais fazem a mediação entre o mundo corriqueiro e o Paraíso Terrestre. A ausência do Inferno na Vida de Santo Amaro reforça na narrativa a cisão entre o Aqui e o Além e a inacessibilidade deste último aos vivos, em sua manifestação terrena ou celeste, demonstrando uma inclinação realista do texto. A trajetória de Santo Amaro parece de imediato exigir uma interpretação simbólica. As etapas de sua topografia orientando-se primeiro da esquerda para a direita, e depois, de baixo para cima, representam em escala crescente as conquistas da jornada ascética. A peregrinação tridimensional de Amaro representa bem o progresso da conquista da beatitude, que passa pela descida da humilhação e a subida espiritual em direção ao Criador. No entanto, a própria orientação realista do texto torna discutível uma interpretação apenas simbólica das intenções do suposto "autor" ao compor os espaços da narrativa.

A representação dos espaços na Vida de Santo Amaro pede uma consideração a um só tempo simbólica e objetiva. O realismo dos espaços terreno e ultraterreno fundamenta esta interpretação, pois demonstra uma relação ponderada com a natureza do espaço que ultrapassa o nível da fabulação e da reflexão dentro de um universo fechado de representações culturais. Exemplo específico é a representação do mar, elemento de ligação entre todos os espaços. Ao longo 
das mudanças na trajetória de Amaro, o mar permanece o mesmo, não perde suas características naturais ambivalentes: mesmo após a passagem pelo Mar Vermelho - a partir do qual os homens mudam - continua perturbador. A inalterabilidade do mar reforça seu realismo. Apesar de suas ameaças, o mar na legenda não é um espaço que aprisiona as imaginações. Para além dele, existe sempre mais terra e mais esperança.

O sonho de São Brandão se conclui depois do retorno ao ponto de partida de sua aventura, da divulgação do que encontrou e, finalmente, de sua morte que assegura a realização definitiva do santo com sua entrada no Paraíso Celeste. A peregrinação de Amaro não inclui retorno a um estado inicial, nem menciona a morte como realização ou consolidação de uma situação de fato, como acontece com Brandão. O destino de Amaro se concretiza na "terra" que seus amigos povoam, e que ele mesmo fertiliza com a escudela trazida do Paraíso Terrestre. Desde Sérgio Buarque de Holanda, muito já se comentou o "realismo desencantado" dos portugueses ${ }^{14}$. A Vida de Santo Amaro nos coloca nos primórdios deste realismo, ainda provido de encanto, e pode ajudar-nos a entender as razões de seu fenecimento, bem como oferece dados para pensarmos no tema clássico do atraso português dentro do panorama histórico europeu. A experiência histórica que dá corpo à legenda de Amaro nos põe em contato com uma precoce concepção realista do mundo, motivada, porém, por uma especificidade histórica cujo sucesso promoverá sua própria paralisia.

À luz dos estudos produzidos durante este século que articularam as motivações da aventura ultramarina ibérica à tradição mítica da Europa ocidental, seria impossível não pensarmos na relação paradigmática entre a Vida de Santo Amaro e o contexto de sua última vernacularização, decisivo na história do expansionismo português. No entanto, a narrativa tem uma história retrospectiva conhecida que a marca indelevelmente, e que não deve ser deixada em segundo plano, em favor de uma interpretação progressista. Mais do que um paradigma do futuro conquistador, a Vida de Santo Amaro é o relato da experiência conquistadora que forneceu modelo político, moral e econômico para as grandes aventuras marítimas, e mais amplamente para a própria experiência histórica portuguesa: a Reconquista.

A forte ligação que existiu ao longo da Reconquista portuguesa entre a retomada de territórios - feita com freqüência através de deslocamentos marítimos -, a peregrinação e a fixação de casas religiosas, marca a geografia da legenda de Santo Amaro. Na primeira metade do século XII o pequeno território do Condado Portucalense, situado entre o Douro e o Mondego, estende-se num processo sem retorno. Nesta fase crucial da Reconquista, Cister se ocupa das terras situadas ao norte do rio Tejo. Assim, esta casa, notória por sua relação ousa- 
da com os espaços incivilizados e por seu questionamento prático do imobilismo ${ }^{15}$, instalou-se numa região de significativa condição intermediária entre o Norte e o Sul, o interior e o litoral, mas também - à custa dos elementos cristãos e muçulmanos envolvidos no processo de Reconquista - entre o Oriente e o Ocidente. O mosteiro de Alcobaça (1153), cujas dimensões soberbas demonstram sua importância simbólica e real para a empresa cisterciense ${ }^{16}$, foi construído próximo ao limite extremo das conquistas de entre Mondego e Tejo, entroncamento de horizontes simultaneamente geográficos, temporais e culturais.

A Reconquista irmana-se com a vocação cisterciense em seu desenraizamento espacial e parental. Juntas, fornecem um quadro de unidade geográfica e social aos grupos humanos envolvidos pelo processo de conquista e povoamento. $\mathrm{O}$ mito do Paraíso Terrestre, atualizado pela experiência histórica portuguesa, aparece na vida pia de Amaro forjando um outro, o mito da unidade portuguesa. Esta interpretação é autorizada pelo fato de a versão portuguesa da legenda suprimir a informação da origem asiática de Santo Amaro, o que não acontece no exemplar espanhol. O ocultamento desta informação torna toda a geografia do texto imprecisa, fazendo-a passível de interpretação. Por sua imprecisão, a geografia da legenda pode alargar-se, fundindo simultaneamente espaço mítico, espaço real conquistado e espaço almejado. Vasta fronteira que o mito cristão da origem oriental do homem e a atração da civilização urbana do adversário muçulmano ${ }^{17}$ alimentam. Mito e história convergem na legenda alargando os horizontes da peregrinação de Amaro.

A vontade e a intenção narrativa por detrás da Vida de Santo Amaro parecem evidentes. Em primeiro lugar, por esta hagiografia ocupar-se tão pouco da memória do santo e tanto de sua trajetória. Em segundo lugar, pela própria necessidade de reciclagem do herói conquistador náutico. A viagem de São Brandão, embora bem conhecida em Portugal, adaptava-se mal à idealização desejada. Era preciso uma tradição adaptada aos sentidos da "peregrinação" histórica portuguesa. Uma das especificidades da Vida de Santo Amaro, que mostra este enquadramento histórico da legenda, é a orientação geográfica da narrativa. Os Imrana irlandeses - a cuja tradição está ligada a Ilha de São Brandão ${ }^{18}$ - retratam viagens para ilhas situadas a Oeste. Amaro, entretanto, dirige-se para onde nasce o sol. Resposta mítica à orientação da geografia maravilhosa cristã mas também duplamente histórica. Em primeiro lugar, diante da atração exercida pelo fausto oriental, que a proximidade muçulmana confirmava ${ }^{19}$. Em segundo lugar, devido à experiência real, de formação de uma frota marítima a partir do século XIII ${ }^{20}$, cuja orientação mercantil posterior confirma o fascínio do Leste, foco da ambição colonial subseqüente e objeto de especial apreço dentro do futuro Império Português. 
Ao longo do processo de Reconquista, a proximidade muçulmana e a influência cistercience fomentaram o precoce realismo português, em cuja peculiaridade histórica encontraremos a razão de seu futuro desencanto. A Vida de Santo Amaro aponta para uma antecipação dos portugueses num realismo, apenas posteriormente desenvolvido no restante da Europa ocidental. No entanto, através da legenda estudada, percebe-se que o papel histórico desempenhado por esse realismo parece específico, uma vez que o sucesso da experiência histórica transformada em modelo conduziu o próprio processo histórico português à esclerose. As formas da nacionalidade forjadas sobre o conjunto mito e experiência histórica, herança tradicional e ideologia, consagraram-se num realismo saudosista, realimentado pela influência cristã.

As influências históricas que pressionaram a conformação da narrativa estudada fazem com que a peregrinação de Amaro vá além da simples busca por um lugar paradisíaco e sua fruição passiva. A aventura de Amaro culmina implicitamente numa interessante fusão entre Paraíso Terrestre e Terra Prometida, o que dá um significado especial a esta apropriação do mito paradisíaco. Devemos esta associação ao papel da ordem cisterciense durante a Reconquista e sua interpretação particular dessa experiência portuguesa. A terra em que Amaro se fixa precisa ser conquistada, como a boa terra que "mana leite e mel" do passado bíblico, como a Jerusalém a ser libertada a leste da cristandade e como os estabelecimentos cistercienses e a Reconquista fizeram com os territórios pelos quais passaram. Através da fusão entre o além Paraíso Terrestre e a terrena Terra Prometida, o mito é flexionado em direção ao realismo. Na leitura cisterciense da busca do Paraíso Terrestre, o circuito de peregrinação deságua na conquista e no povoamento de um território inscrito na história, adquirido de forma realista à semelhança da caracterização bíblica da Terra Prometida. O convite sobrenatural desencadeia a peregrinação misticamente orientada, mas a conquista e o povoamento são decisão de Amaro. A escudela de terra milagrosa não lhe foi oferecida, ele a pediu: conquistou-a e, a seu arbítrio, utilizou-a.

A pressão demográfica e as carências materiais do território português já foram bastante citadas como motores de seu ímpeto conquistador. Na Vida de Santo Amaro vemos a função que o material mítico atualizado por uma experiência histórica, enaltecida política e religiosamente pelos meios sociais dominantes, exerce no incremento ao mesmo processo. A comunidade social e política que desponta ao longo da conquista do território torna este movimento, em si mesmo, o paradigma do desenvolvimento histórico subseqüente, pela sua adaptabilidade à função de meio realizador da unidade nacional. Concórdia, conquista e povoamento cimentam a identidade neste discurso cisterciense de influência monárquica. A Vida de Santo Amaro atesta que o realismo português de fato 
estabeleceu-se precocemente, mas a sua forma, longe de ser predominantemente laica, envolve-o numa relação religiosa inextricável. Diferentemente das representações modernas de idealização social como a de Thomas More - em que a conquista maior desloca-se do espaço para a mudança interior do homem -, para Amaro o alvo primeiro ainda é um "lugar". Assim, seu idealismo não se apresenta radicalmente alterado pelo processo de interiorização que deságua na autonomização da consciência moral, como acontecerá com More. Deste ponto de vista, o realismo português mostra-se atrelado à tradição medieval, e não à modernidade.

É preciso lembrar que a experiência de disciplinamento territorial de Cister em Portugal atua mais como instrumento de senhorialização que de evangelização ${ }^{21}$. A um só tempo simbólica e real, a trajetória de Amaro - versão náutica do cavaleiro errante - associa corpo e alma na conquista de um "lugar". Produto histórico da aliança político-religiosa e do arranjo ideológico que uniu o guerreiro, o navegador, a monarquia e a Igreja monástica na aventura de conquista portuguesa, o cavaleiro errante, que brota do contexto mais amplo de deslocamentos europeus a partir da Idade Média central, pode ter sua ação definida como "resposta ao desafio do Desconhecido, do Exterior e do Outro, que uma vez cumprida, faz se expandir no seio deste Desconhecido, deste Exterior e do universo destes Outros um núcleo de clareza e de significado em torno do qual o caos começa a ordenar-se"22. Mas na Vida de Santo Amaro o cavaleiro errante não se completa na "figura laicizada do Homo viator" güidade tipicamente medieval derivada de um mundo mergulhado no religioso e pressionado pela escassez de terras. A Reconquista e Cister cumpriram funções religiosas, políticas e econômicas semelhantes e complementares, disciplinando a sociedade através do ordenamento territorial e espiritual, assimilando filhos sem herança, fornecendo-lhes meio de ajustamento através do parentesco artificial e estabelecendo limites à sociedade laica através da manipulação do parentesco biológico e artificial, estreitando as solidariedades entre os monges e a aristocracia - já fortes em razão de sua proximidade ao longo da cruzada ibérica -, fornecendo um mito e uma ideologia a seu estabelecimento.

Paul Zumthor propõe a idéia de que a Reconquista tenha atrasado a penetração da figura do cavaleiro errante veiculada pela literatura francesa na Península Ibérica ${ }^{24}$. Caso as considerações do autor sejam válidas, particularmente para Portugal, podemos presumir a influência parcial dos modelos desta literatura sobre a Vida de Santo Amaro. Corrobora com isso a ligação que esta viagem de santo ao Paraíso Terrestre demonstra ter com o tema da "busca do Graal". A súbita mudança de curso na Vida de Santo Amaro, que evocamos a princípio, coincide com o enxerto do tema da conquista de um cálice maravilhoso, que se 
não é o alvo da viagem acaba tornando-se fundamental em seu desfecho surpreendente. Mas o graal-escudela de Amaro conserva tanto a característica do dysgyl, "prato da fartura" gaulês que aparece no Perceval (c.1180) de Chrétien de Troyes, quanto o aspecto cristão do cálice de José de Arimatéia da Estoire dou Graal (c.1200) de Robert de Boron. Na legenda de Amaro, as duas propriedades se harmonizam como instrumento de uma autoridade religiosa firmada na interioridade do herói conquistador e não na Igreja. Interioridade e materialismo convivem harmoniosamente na composição a um só tempo cristã e folclórica que é a legenda portuguesa de Santo Amaro.

A Terra Prometida de Amaro, todavia, não é a mesma região em que se encontra o Graal, como acontece na Estoire dou Graal de Robert de Boron, mas um outro lugar, longe tanto da terra de origem dos viajantes quanto do lugar maravilhoso em que a prenda preciosa é recolhida. A terra natal e a terra de povoamento, tão distantes, fundem-se imaginariamente numa mostra de abstração fundamental para a concepção da nacionalidade e da colonização. A atração pelo Oriente encontra na ideologia cristã cimento poderoso. O ritualismo importado de além-Pirineus e os limites sociais advindos das regras cristãs de parentesco dão unidade a uma formação social nova, um sentido unificador e uma autoridade reconhecida a um só tempo leiga e religiosa, urbana e rural. As diferenças na terra recriada por Amaro não chegam a constituir oposições. Em seu mundo de moderno desapego que deixa o jardim do Além para depois da morte, existe complementaridade e harmonia. Diferentemente da Inglaterra, onde o cálice de Cristo cabe ao rei - e assim serve de fundamentação para a legitimidade da dinastia reinante -, a escudela de Amaro serve a toda uma população ordenada pelo cristianismo. No entanto, o impulso desenraizador e o ideal de harmonia social que a legenda de Amaro divulga, sob influência cisterciense traziam um modelo de relações e realismo religioso que rapidamente seria superado pela experiência de além-Pirineus. A Vida de Santo Amaro nos mostra, contudo, como esta influência foi fundamental ao espírito em que se deu o estabelecimento da monarquia e da unidade portuguesas.

O início da tradução para o vernáculo dos acervos monasteriais portugueses se dá no século XIV, acompanhando o processo de fortalecimento da monarquia. A ordem cisterciense que chegara a Portugal no século XII experimenta, neste primeiro século de implantação, o apoio de Afonso Henriques, que encontrou na ordem importante fator de uniformização do clero e, sobretudo, veículo consolidador de conquistas. Apesar de a ordem cisterciense propor o isolamento de seus membros, esta ação resultava, de fato, num movimento de difusão de povoamentos e de desbravamento territorial. Nos séculos seguintes, no entanto, a dependência de Cister em relação à monarquia se acentua em face do 
declínio geral da ordem e da influência crescente dos mendicantes junto ao governo português. A Vida de Santo Amaro é produto do encontro da ética cisterciense com os desígnios da monarquia portuguesa. A investigação levada a cabo até o momento não nos permite afirmar que o documento relate uma relação privada de conflitos entre Cister e a monarquia. É certo, todavia, que a vernaculização do documento e a forma pela qual o conhecemos devem ser examinadas como fruto de pressões externas à vida do claustro. Cabe-nos perguntar qual o sentido e a profundidade das alterações produzidas sobre uma hipotética versão arquetípica da legenda, questão cuja resposta depende de um trabalho mais extenso de rastreamento das versões da mesma, e do estudo de outros relatos de viagens marítimas ao Além.

As ingerências monárquicas e cortesãs sobre a Vida de Santo Amaro ainda precisam ser observadas à luz da relação direta existente entre as cortes portuguesa e francesa - e sua tradição literária entre os séculos XIII e XIV -, e da relação menos direta que existe entre o substrato agrário e céltico de suas literaturas. Sabemos que a dinastia Plantageneta serviu-se da literalização de tradições folclóricas bretãs realizadas em língua vernácula nos ambientes cavaleirescos inglês e francês para se legitimar. Empreitada para a qual se mostrou ideal, sobretudo, o ciclo cristianizado de aventuras de busca do Graal. Lembremos que a viagem de São Brandão faz parte de um dos primeiros episódios desta relação dos plantagenetas com a literatura folclórica. Podemos nos perguntar se a legenda examinada se liga a um processo similar em Portugal: embora a monarquia não seja abertamente citada, a legenda traz em sua conclusão o beneficiamento de uma região urbana abençoada com terra do Paraíso e com a harmonia entre leigos e religiosos, monges e sacerdotes. Ambiente dinâmico e promissor diretamente ligado ao processo de formação da unidade e identidade portuguesas. A legenda de Amaro é surpreendentemente precisa em termos dogmáticos, explicitando didaticamente significados litúrgicos e diferenciando atributos santos e divinos. Neste aspecto, também mito e relato hagiográfico se misturam e servem de suporte privilegiado a favor do aperfeiçoamento da doutrina entre os fiéis e da legitimação política. Mais que a memória do santo, o relato visa a estes dois alvos através de seu simbolismo, simultaneamente, político e religioso. É ao empreendimento humano que está votada a escudela do Paraíso, este graal contendo terra, pleno de vitalidade, cujo emprego Amaro recria. Mas se em sua representação realista do Além os portugueses tomam o Paraíso por perdido, o modelo criativo segue sendo a terra prodigiosa.

Dados documentais indicam que o ciclo completo do Graal já era conhecido em Portugal desde o início do século XIV ${ }^{25}$. As aproximações que podem ser feitas entre esta literatura e a legenda que abordamos são evidentes. Embora os 
elementos que caracterizam esta aproximação sejam importantes, nos limitaremos, por hora, a apontar três diferenças muito significativas. A anteposição entre o sacerdócio de virtude e o sacerdócio ordenado e oficial ${ }^{26}$ é enfraquecida na legenda de Amaro. Nela, as cidades vicejam altivas sob a autoridade de sacerdotes. Aos eremitas e santos se destina a marginalidade santa dos visionários do $\mathrm{Pa}$ raíso. O graal de Amaro, por outro lado, também não se liga prioritariamente a um rei ou a um cavaleiro, mas a toda uma população. Como na Estoire dou Graal, o encontro do santo receptáculo dá origem a novos tempos. Mas os novos tempos para Amaro começam em outra "terra", onde ele e seus companheiros são "como orfaãos sem padre e sem madre e sem cõselho" (p.515). Como não pensar neste relato como um registro da Reconquista e em seu potencial paradigmático para a experiência colonial? Sintomaticamente, a legenda de Santo Amaro, sob as formas apontadas, parece ser exclusiva dos países ibéricos.

O mito serve de suporte a uma narrativa em que o tradicionalismo se imbrica de forma curiosa com o novo. As ambigüidades na caracterização de Amaro também são fruto desta mistura. Dessa forma, a interpretação da legenda se soma à clássica discussão sobre o atraso português em relação a outras regiões da Europa ocidental durante o final da Idade Média, e à interpretação de sua "valentia" marítima. Ao atraso econômico, como a força motivadora dos gestos "modernos" da história tardomedieval portuguesa, a legenda de Amaro traz alternativas saídas de seu tradicionalismo cultural e de sua história particular recente. Na média duração da história escrita da Vida de Santo Amaro ainda falta um maior esclarecimento das influências que, entre as dinastias de Borgonha e Avis, a Reconquista e os Descobrimentos, foram decisivas sobre a forma pela qual o relato chegou até nós e para uma melhor datação da legenda.

A Vida de Santo Amaro tem um circuito de produção e difusão conhecido que vai do século XIII ao XVI. Sua história, no entanto, inclui temáticas que a inserem numa duração temporal mais longa e num espectro de contribuições culturais que ultrapassam a experiência nacional portuguesa, na qual vemos tomar corpo e importância sua difusão escrita em língua vernácula. Apóiam esta posição a forma como se liga a relatos muito antigos de viagens marítimas maravilhosas, a envergadura mítica de sua temporalidade, o tema altomedieval do contemptus mundi, e a fusão em um dos trechos da legenda de Amaro com uma outra fonte hagiográfica referente a Brígida, santa de origem irlandesa. Este núcleo de temas e significados antigos dá suporte à operância religiosa e política ampla do relato. Tanto um quanto outro propósito se servem de um mesmo veículo, um relato tradicional de viagem marítima ao Além e da atração que as possibilidades do trânsito entre o Aqui e o Além exercem sobre a cultura do período e, especifica- 
mente, o fascínio que tem sobre a aristocracia portuguesa de então, o tema da conquista da escudela e o encontro entre o perfil heróico do santo e o do cavaleiro monge. Como não especular a respeito de seu apelo sobre uma nobreza ainda irrequieta no século $\mathrm{XV}$, que via nos territórios mouros - primeiramente em solo lusitano e depois na África - meios para a realização de seu ímpeto por terras e saques $^{27}$ ? Público sequioso por terras e rincões para o estabelecimento de núcleos de vida santa e alvo do disciplinamento monárquico em cuja intenção, provavelmente, a legenda de Amaro foi traduzida para o vernáculo.

A forte presença das ordens mendicantes em Portugal e seu prestígio político e social asseguraram a valorização de sua atuação histórica nos trabalhos dedicados aos últimos séculos da história medieval portuguesa. Este fato, aliado à efetiva dependência monárquica e aristocrática dos mosteiros, talvez tenha nos levado a subestimar a importância de Cister no processo de formação da identidade portuguesa e nos desempenhos espirituais, políticos e sociais mais arrojados de Portugal após o século XII. Como a prática cisterciense, a aventura de Amaro da busca pelo isolamento e pela experiência pessoal com Deus redundou numa empresa civilizacional muito mais ampla. Muito embora a luta de Amaro seja espiritual e contra si mesmo, sua conquista é a terra. Seus resultados se destinam a muitos. De forma diferente do Paraíso Terrestre fortemente cavaleiresco, o "paraíso" construído por Amaro é socialmente mais amplo. Nele, a terra e a autoridade religiosa asseguram a unidade. As subversões que a intertextualidade trouxeram à narrativa colocam seu herói reencontrando-se consigo mesmo em uma origem nova que não deriva da ancestralidade, mas da terra e do espírito.

É elementar o sentido de consolo e esperança que as representações paradisíacas ganham em meio às carências e impossibilidades do homem medieval. Amaro perde suas dádivas depois de vivenciá-las em sonho e na realidade fugidia. O consolo e a esperança que eram buscados no Paraíso se transformam no final surpreendente da Vida de Santo Amaro. O santo, ao pressentir o desespero aterrador que toma conta de seus companheiros sozinhos em terra estranha após sua ausência, envia-lhes uma mensagem de conforto paradigmática do consolo que ele mesmo buscará ao perder o Paraíso: povoar (p.515). A autoridade do santo e a ligação supracarnal que estabeleceu com seus companheiros de viagem fornecem as bases abstratas para seu desapego a uma identidade baseada na genealogia e na ligação a um território ancestral.

O século XIV sela o surgimento das primeiras expedições além-mar portuguesas que, a partir das Canárias, atingirão o Oriente no final do século XV através da circunavegação da África. No século XIV, a legenda de Amaro também ganha sua primeira versão vernácula. A cronologia precisa de sua composição e 
a relação das forças que a influenciaram ao longo deste período permanecem mal definidas. Pretendemos aqui apenas esboçar possibilidades interpretativas desta fonte bastante conhecida, mas pouco abordada com exclusividade, à luz de sua inserção na problemática referente às especificidades do desenvolvimento histórico português, dos Grandes Descobrimentos e suas razões culturais. A ligação entre o relato e o processo de Reconquista estabelece motivações para o envolvimento português na aventura náutica atlântica, que ultrapassam o contexto de crise que no mesmo século XIV pode ser tomado como causa última deste gesto. Para além deste fator conjuntural, o desenvolvimento histórico estava ligado a valores e ideais que o remetiam nesta direção não de forma fatal, mas pela força da experiência ao longo da qual foram forjados os elementos essenciais, materiais e míticos, da unidade portuguesa.

\section{NOTAS}

* Sou grata ao Prof. Segismundo Spina que, partilhando com generosidade sua erudição irretocável, concedeu-me orientações preciosas para a leitura de trechos da Vida de Santo Amaro. Agradeço também à amiga e mestra Yone de Carvalho pela leitura que fez deste texto e por seus comentários intelectualmente estimulantes e enriquecedores.

${ }^{1}$ DUBY, G. "A história dos sistemas de valores". In DUBY, G. Idade Média, Idade dos Homens, do amor e outros ensaios. São Paulo: Cia. das Letras, 1989, p.134.

${ }^{2}$ LOURENÇO, E. Mitologia da saudade. São Paulo: Cia. das Letras, 1999, pp.10-12 e 14.

${ }^{3}$ Utilizamos o termo legenda em seu sentido etimológico "o que se deve ler" e não como sinônimo de lenda. A hagiografia medieval, como mostra E.B. VITZ, "Vie, légende, littérature: traditions orales et écrites dans les histoires des saints”, Poétique, 72, 1987, pp.387-402, estava indissociavelmente ligada tanto à oralidade quanto à escrita. Dessa forma a aplicação do termo legenda reporta-nos a um dos aspectos fundamentais da matéria hagiográfica, composta por escrito pelos eruditos cristãos para ser depois lida em voz alta solitariamente ou para uma assistência que poderia ser de leigos, religiosos ou mista. Tal aspecto ressalta a existência de uma orientação específica na composição e destinamento da narrativa. A própria vernacularização da Vida de Santo Amaro aponta para a busca de uma ampliação de sua leitura, e portanto, para um alargamento de seu caráter de legenda.

${ }^{4}$ KLOB, O.(ed.) “A vida de sacto Amaro”. Romania, 30, 1901, pp. 504-518.

${ }^{5}$ Não pudemos consultar para a elaboração deste artigo as edições críticas mais recentes preparadas por E. HEINEN, Die altportugiesische Amaro-Legende. Kritische Ausgabe der Altesten Fassung, Münster, ed. do autor, 1973 e por E.M.B. da SILVA em A.A.NASCIMENTO, "Navegação de São Brandão" nas fontes portuguesas medievais, Lisboa: Colibri, 1998, pp. 243-281.

${ }^{6}$ Referimo-nos, por exemplo, às interpolações que sugerem a destinação pública do texto, como as evocações ao canto litúrgico. KLOB, O. op.cit., pp. 508 e 517.

${ }^{7}$ WILLEMART, P. “Intenção do autor, vontade do autor e lógica do texto.” In Revista do Instituto de Estudos Brasileiros. 33, 1992, pp. 128-135 e ZUMTHOR, P. A letra e a voz. A "literatura” medieval. São Paulo: Cia das Letras, 1993.

${ }^{8}$ LE GOFF, J. “Aspects savants et populaires des voyages dans l'au-delá au Moyen Age”, In LE GOFF, J. L'Imaginaire médiéval. Paris: Gallimard, 1985, pp. 103-119; LE GOFF, J. “Cultura clerical e tra- 
dições folclóricas na civilização merovíngia" In LE GOFF, J. Para um novo conceito de Idade Média. Lisboa: Estampa, 1980, pp. 207-219 e GUREVIC, A. J. “Au Moyen Age: conscience individuelle et image de l'au-delá”. In Annales ESC, 2, 1982, pp. 255-275.

${ }^{9}$ Chamamos de mais evolutiva a capacidade que as narrativas escritas têm de se prestarem a uma instrumentalização mais consciente e dinâmica de seu conteúdo, o que permite e acelera um controle mais eficiente do processo de transformação de seus sentidos e significados.

${ }^{10}$ BENEDEIT. Le voyage de Saint Brandan. Ed. I. SHORT e B. MERRILEES, Paris, Union Générale d’Éditions, 1984. Ver também SELMER, C. (ed.). Navigatio sancti Brendani abbatis. Dublin: Four Court Press, 1989.

${ }^{11} \mathrm{BAR}, \mathrm{F}$. Les routes d'autre monde. Descents aux enfers et voyages dans l'au-delá. Paris: PUF, 1946, pp. 78-92.

${ }^{12}$ GATTO, G. "Le voyage au Paradis". In Annales ESC, 4, 1979, pp. 929-941.

${ }^{13}$ LE GOFF, J. O nascimento do Purgatório. Lisboa, Estampa, 1993 e SCHMITT, J.C. Les revenants. Les vivants et les morts dans la société médiévale. Paris: Gallimard, 1994.

${ }^{14}$ HOLANDA, S. B. de. Visão do Paraíso. Os motivos edênicos no descobrimento e colonização do Brasil. São Paulo, Brasiliense, 1996, e GIUCCI, G. Viajantes do maravilhoso. O Novo Mundo. São Paulo: Cia. das Letras, 1992.

${ }^{15}$ CORTESÃO, J. Os descobrimentos portugueses. Lisboa: Imprensa Nacional $\backslash$ Casa da Moeda, 1990, v.1, pp. 77- 86 e 195, 204, destaca o papel cultural dos franciscanos no estabelecimento de uma nova relação com o espaço e com a natureza como capital ao expansionismo português. Para tanto, contrapõe o movimento mendicante ao monaquismo de reclusão e eremítico que, segundo ele, "opu214 nha-se a toda idéia de expansão" refletindo "o regime de economia privada em que nasceram”(p.77). Ressalvadas as diferenças de papel histórico das duas ordens, no entanto, não podemos excluir Cister de um movimento que, se é diferente da expansão marítima subseqüente em vários aspectos, no entanto, como pretendemos mostrar neste texto, o precedeu e fundamentou cultural e ideologicamente. Embora de fato a ordem cisterciense tivesse como um de seus ideais mais importantes o isolamento, sua história prática vai em outras direções, como ilustra a carreira exemplar de São Bernardo. Conforme mostra M. A. A. MARQUES, Estudos sobre a ordem de Cister em Portugal. Lisboa: Colibri \Faculdade de Letras da Universidade de Coimbra, 1998, pp.16 e 181-195, a ordem cistercience em Portugal desempenhou importante papel no processo de povoamento e de desenvolvimento econômico das regiões conquistadas. Tal participação não esteve limitada a seus próprios domínios, mas irradiou-se geograficamente estimulando atividades que iam além da agricultura, chegando ao comércio e à construção naval, como acontece no caso específico de Alcobaça.

${ }^{16}$ A igreja de Alcobaça é a maior de Portugal e reconhecidamente um dos mais significativos exemplares da arquitetura cisterciense européia. SERRÃO, J. Dicionário de História de Portugal. Lisboa: Iniciativas, 1971, v.1, p.83.

${ }^{17}$ MATTOSO, J. “A formação da nacionalidade”. In História e antologia da literatura portuguesa, séculos XIII-XIV. Lisboa: Fundação Calouste Gulbenkian \Serviço de Biblioteca e Apoio à Leitura, 1984, p.17.

${ }^{18}$ A Ilha de São Brandão continuou constando da cartografia européia e atraindo aventureiros até o século XIX, aparecendo pela última vez no Atlas de Stieler, de 1867. ALBUQUERQUE, L. de. Introdução à história dos descobrimentos portugueses. Lisboa: Europa-América, 1989, p.155.

${ }^{19}$ ALBUQUERQUE, L. op. cit., pp.72-83.

${ }^{20}$ MATTOSO, J. Fragmentos de uma composição medieval. Lisboa: Estampa, 1987, p.297. 
${ }^{21}$ MATTOSO, J. Identificação de um país. Ensaio sobre as origens de Portugal (10961325). Lisboa: Estampa, 1985, v.1, pp.412-413.

${ }^{22}$ ZUMTHOR, P. "De Perceval à Don Quichotte. L'espace du chevalier errant”. In Poétique. 72, 1987, p.263. Ver também CHAUNU, P. "Les romans de chevalerie et la conquête du Nouveau Monde". In Annales ESC. 2, 1955, pp.216-230.

${ }^{23}$ ZUMTHOR, P. op. cit., p.262.

${ }^{24}$ Idem, p.267.

${ }^{25}$ SARAIVA, A. J. O crepúsculo da Idade Média em Portugal. Lisboa: Gradiva, 1988, pp.62-63.

${ }^{261}$ dem, p.70.

${ }^{27}$ ALBUQUERQUE, L. de. op. cit., pp.82-83.

Artigo recebido em 06/1999. Aprovado em 09/2000. 